\title{
Balance historiográfico: revoluciones, movimientos sociales y vida rural en Sinaloa, México, 1980-2013
}

\author{
Rafael Santos Cenobio ${ }^{1}$
}

\section{RESUMEN}

Recebido: 31.05 .2019

Aceito: 13.11 .2019

Publicado: 13.01 .2020

Este trabajo busca realizar una revisión historiográfica de la literatura producida en Sinaloa y en México en los últimos treinta años del siglo XX y los primeros trece años del siglo XXI, sobre revoluciones, movimientos sociales, revueltas, guerrillas y agroindustria. Para el análisis de la literatura sinaloense, primero se realizó una clasificación por ejes temáticos, luego se describió y contrastó autores, después se elaboró una síntesis discursiva y finalmente se identificaron las diferentes corrientes historiográficas. Los enfoques observados fueron la movilización de recursos, oportunidades políticas, nuevos movimientos sociales, hegemonía (Sánchez, 2011, 2012, 2013a, 2013b; Santos, 2013; Cázares Aboytes, 2005a y 2005b), descampesinismo (Rubio e Hirata, 1985; Hirata, Rubio, Meza, 1978; Quevedo, 1996; Meza, 2002, 1989; Posadas, 1978, 1980, 1983, 1985, 1989, 2005), institucionalismo, redes y élites (Aguilar Alvarado, 2000, 2003; Martínez, 2004; Brito, 2005; Cerutti, 2000; Aguilar Aguilar, 1993, 2003, 2008; Padilla, 1996; Frías, 2008). Los estudios analizados centran su mirada en actores populares como en las élites, lo cual hace que este artículo concluya con una visión integral de la región sinaloense.

Palabras clave: revolución, historiografía, movimientos sociales, revueltas rurales

Balanço historiográfico: revoluções, movimentos sociais e vida rural em Sinaloa, México, 1980-2013

\section{RESUMO}

Este trabalho busca realizar uma revisão historiográfica da literatura produzida em Sinaloa e no México nos últimos trinta anos do século XX, e nos primeiros treze anos do século XXI, sobre revoluções, movimentos sociais, revoltas, guerrilheiros e agroindústria. Para a análise da literatura sinaloense, foi realizada a classificação por eixos temáticos, depois os autores foram descritos e contrastados, então foi desenvolvida uma síntese discursiva e as diferentes correntes historiográficas foram finalmente identificadas. As abordagens observadas foram: mobilização de recursos, oportunidades políticas, novos movimentos sociais, hegemonia (Sanchez, 2011, 2012, 2013a, 2013b; Santos, 2013; Cázares Aboytes, 2005a e 2005b), descampesinismo (Rubio e Hirata, 1985; Hirata, Rubio, Meza, 1978; Quevedo, 1996; Meza, 2002, 1989; Posadas, 1978, 1980, 1983, 1985, 1989, 2005), institucionalismo, redes e elites (Alvarado, 2000, 2003; Martinez, 2004; Brito, 2005; Cerutti, 2000; Aguilar Aguilar, 1993, 2003, 2008; Padilla, 1996; Frio, 2008). Os estudos analisaram o foco em atores populares como elites, o que traz este artigo para uma visão abrangente da região de Sinaloense.

Palavras-chave: Revolução, Historiografia, Movimentos Sociaias, Revoltas Rurais.

Historiographical Balance: revolutions, social movements and rural life in Sinaloa, Mexico, 1980-2013

\section{ABSTRACT}

This work seeks to carry out a historiographic review of the literature produced in Sinaloa and Mexico in the last thirty years of the twentieth century and the first thirteen years of the twenty-first century, on revolutions, social movements, revolts, guerrillas and agribusiness. For the analysis of Sinaloense literature, a classification by thematic axes was first performed, then authors were described and contrasted, then a discursive synthesis was elaborated and finally the different historiographic currents were identified. The approaches observed were the mobilization of resources, political opportunities, new social movements, hegemony (Sanchez, 2011, 2012, 2013a, 2013b; Santos, 2013; Cázares Aboytes, 2005a and 2005b), decampesinism (Rubio e Hirata, 1985; Hirata, Rubio, Meza, 1978; Quevedo, 1996; Meza, 2002, 1989; Posadas, 1978, 1980, 1983, 1985, 1989, 2005), institutionalism, networks and elites (Aguilar Alvarado, 2000, 2003; Martínez, 2004; Brito, 2005; Cerutti, 2000; Aguilar Aguilar, 1993, 2003, 2008; Padilla, 1996; Frías, 2008). The studies analyzed focus on popular actors such as elites, which makes this article conclude with an integral vision of the Sinaloa region.

Keywords: Revolution, historiography, social movements, rural revolts.

${ }^{1}$ Universidad Autonoma de Sinaloa, Mexico. Correo electronico; rafaelsantos921@gmail.com 


\section{Introducción}

Este trabajo busca realizar una revisión historiográfica de la literatura producida en Sinaloa y en México en los últimos treinta años del siglo XX y los primeros trece años del siglo XXI, sobre revoluciones, movimientos sociales, revueltas, guerrillas y agroindustria.

El trabajo inicia con un análisis de los trabajos ya clásicos, que versan sobre revoluciones, movimientos sociales y revueltas rurales a una escala más internacional y nacional. De todo esto, se desprenden varias corrientes historiográficas, por ejemplo, desde la Sociología Histórica se piensa que las revoluciones china, francesa, norteamericana e inglesa se produjeron por una combinación de factores estructurales, motivaciones individuales y colectivas, y relaciones internaciones. Los resultados revolucionarios fueron variados, ya sea socialismo, capitalismo o fascismo. Otra visión, influida por la anterior, argumenta que los campesinos durante el siglo XIX, se rebelaron esporádicamente motivados por factores estructurales, movilización de recursos y oportunidades políticas, pero no se atrevieron a insurreccionarse masivamente, esperaron hasta la Revolución mexicana de 1910. En cuanto a los movimientos campesinos y vida rural en México, fue estudiado desde dos posturas opuestas: campesinista y descampesinista. En tanto, la perspectiva de la hegemonía y la cultura, propone estudiar la alta y baja política en un diálogo recíproco.

Las investigaciones en Sinaloa, sobre los movimientos sociales, trabajadores, guerrilla, agricultura comercial y empresarios han sido muy prolíficas, los cuales aparecen condensados en ensayos, tesis, monografías y libros publicados por la Universidad Autónoma de Sinaloa.

Las grandes tendencias de análisis son muy variadas. Los trabajos elaborados en la década de 1980, sobre movimientos campesinos son analizados desde los enfoques marxista-leninista, descampesinista y campesinista. Estas perspectivas planteaban que los campesinos se movilizaron porque existían liderazgos carismáticos, pero sobre todo porque se proletarizaron, al no poder competir con la burguesía local, y para sobrevivir tuvieron que combinar entre trabajo en su parcela y trabajo asalariado.

En la década de 1990 y 2000, en Sinaloa también los obreros fueron estudiados desde la teoría de la movilización de recursos y de la historia social inglesa. En el lapso de 2004 hasta el 2013, las investigaciones sobre movimientos campesinos y estudiantiles, y guerrillas fueron analizados desde las teorías sociológicas de la identidad, agravio moral, la acción colectiva, de la movilización de recursos, la oportunidad política y la historia cultural. Del mismo modo, se han investigado los cacicazgos políticos en Sinaloa, utilizando el concepto de hegemonía, lo cual permite ver la alta y baja política en un constante diálogo.

La línea de la historia empresarial (historia de las familias, élites empresariales y evolución de las grandes empresas agroindustriales) comenzó a desarrollarse en Sinaloa afínales de la década de 1980, se trató de algunas tesis de la primera generación de la Maestría en Historia Regional (19841987) de la Universidad Autónoma de Sinaloa. Pero el auge de las investigaciones se presentó a partir del año 2000, a raíz de la fundación de la Facultad de Historia (1988), la creación del doctorado en Ciencias Sociales (1995), la institucionalización del congreso de historia regional y la publicación de la revista Clío (Aguilar Aguilar y Frías Sarmiento, 2009, p. 16-23). La historia empresarial se abocó a estudiar, el periodo de 1930 a 1960, especialmente por exitoso desarrollo agroindustrial que experimentó Sinaloa, favorecido por los derechos de propiedad, los contratos y las prácticas de la regulación económica, junto a la capacidad empresarial de los agricultores y el incentivo de las políticas públicas. (Aguilar Soto, 2010, p. 280-285).

La metodología seguida para analizar una numerosa cantidad de trabajos fue agruparlos en ejes temáticos, después se describió y contrastó autores, luego se elaboró una síntesis discursiva y finalmente se identificaron las diferentes corrientes historiográficas. En un sentido más específico, las investigaciones se fueron unificando con base a las tendencias o enfoques desde donde se han observado los diferentes fenómenos sociales. Asimismo, se parte de los trabajos que abordan revoluciones mundiales, para luego llegar a los estudios mexicanos sobre rebeliones, revoluciones 
y movimientos sociales, finalmente se concluye con la literatura sinaloense, relacionado con movimientos campesinos, guerrillas y agroindustria.

El trabajo se vertebra en tres ejes temáticos, el primero alude a las revoluciones, movimientos sociales y revueltas rurales en el mundo y en México; mientras que en el segundo se refiere a movimientos campesinos, guerrillas y vida rural en Sinaloa; y el último aborda la historia económica producida localmente.

\section{Revoluciones, movimientos sociales y revueltas rurales}

En esta sección se busca discutir una pléyade de autores clásicos sobre revoluciones y movimientos sociales, destacando diferentes corrientes teóricas y conceptuales. Desde la Sociología Histórica figuran dos visiones que aluden a las grandes revoluciones mundiales. La primera es sustentada por Moore (1973), quien afirma que las revoluciones inglesa, francesa, norteamericana y china se nutrieron de extensos bloques de masas campesinas. Según Moore, para que la gente se rebele es necesario la imbricación de elementos estructurales, motivaciones individuales y colectivas. En ese sentido se distinguen: el capitalismo comercial como aniquilador de los derechos comunales de los campesinos; la persistencia de la lealtad, y solidaridad entre clanes; desastres naturales y mala administración de las burocracias reales; la división entre las élites; y el agravio moral. Este tema es abordado con profundidad en otra de las obras de Moore (1989) donde afirma que, en todas las sociedades, los pobres tienen la capacidad de soportar el sufrimiento, pero al percatarse de un agravio moral crean un sentimiento de injusticia que los lleva a rebelarse. ${ }^{2}$

Es cierto que Moore menciona los conflictos internacionales, pero no es el corazón de su discusión, a diferencia de Skocpol (1984), quien pone énfasis en ellos, pues considera que a partir de allí pueden debilitarse las elites o dividirse provocando el relajamiento de los campesinos. Esta autora discrepa de Moore, al decir que en China no existía una sociedad campesina autónoma, ya que los ricos, bajo una comunidad de mercado directa o indirectamente reclutaban a los campesinos para la realización de actividades religiosas, educativas o para beneficios económicos. ${ }^{3}$

Para Skocpol, a diferencia de Moore, sostiene que las movilizaciones revolucionarias estuvieron motivadas por fuertes grados de solidaridad, organización y autonomía de las aldeas; así como del desplome de la capacidad represiva del Estado, y la división de las élites provocado por los conflictos internacionales; y la alianza entre campesinos con algunos miembros de la élite.

Moore (1989) y Skocpol (1984), sentaron las bases para el surgimiento de teorías como la movilización de recursos y oportunidades políticas. En ese sentido, algunos referentes como Katz (2004) afirman que las revueltas rurales prehispánicas, diferentes a las convulsiones sociales en la colonia, siguieron patrones similares al de los siglos XIX y XX. ${ }^{4}$ Katz (2004) coincide con Skocpol (1984) y Moore (1989) al destacar que para el surgimiento de una revuelta son necesarias las alianzas con los caciques regionales, impugnación a la legitimidad de las autoridades, oposición a las expropiaciones de tierras y las exigencias de tributo. Además, agrega el autor, el concepto de "levantamiento rural" o "revuelta rural" definida como un movimiento donde participan organizaciones o entidades identificables que representan a las clases bajas del campo mexicano: las comunidades de los pueblos, las organizaciones tribales y las organizaciones políticas compuestas por o que representaban a los habitantes rurales.

\footnotetext{
2 Sucede eso, si las necesidades básicas de los afectados no son satisfechas adecuadamente por las autoridades o bien por la reactivación de las experiencias históricas que funcionan como mecanismos de interpretación de una situación de agravio. Los cambios sociales que provocan un sentimiento de injusticia también pueden dividir a las élites, facciones fuera del poder que buscan el apoyo de las masas para desafiar a sus contrincantes.

${ }^{3}$ En China como en Inglaterra los motines contra los impuestos o la corrupción oficial fueron dirigidos por los ricos de la localidad.

${ }^{4}$ Durante la época de los aztecas, además de la división de sus élites, ellos no intentaron adoctrinar religiosamente a la población Mesoamericana, tampoco gozaron de legitimidad frente a sus súbditos. En tanto, los españoles sí lograron mantener una sociedad rural relativamente controlada; aunado a la muerte masiva de indígenas provocados por enfermedades mortales traídos por los conquistadores. Fue al final de la colonia cuando los campesinos se rebelaron, favorecidos por las oportunidades políticas como la intervención napoleónica en España, incremento de la población y división entre las élites. Patrón reproducido en los siguientes siglos, dice Katz.

${ }^{5}$ Implica también que las demandas de los sublevados tuvieran relación con las demandas sociales, económicas, políticas o religiosas de la población rural.
} 
Al igual que Katz, una pléyade de estudiosos (Hart, 2004; Reyna, 2004; y Tutino, 2004), pensaban que las revueltas rurales, desde la época prehispánica hasta 1910, fueron muy focalizadas, cuando pudieron rebelarse masivamente los campesinos, no lo hicieron, luego se dieron cuenta que el Estado nacional y los terratenientes se habían unido, por lo que tuvieron que esperar hasta la Revolución mexicana. Estos historiadores insisten en que las rebeliones y las revueltas rurales, antes del estallido revolucionario, se debieron a la debilidad o la división entre las elites; la intervención francesa y norteamericana en México durante el siglo XIX; y a la expansión de la agricultura comercial, que erosionó la economía doméstica de los campesinos. Hart, agrega que los pobres muchas de las veces no se insurreccionaron, a pesar de que existía división entre las élites o intervención extranjera, porque había un marcado aislamiento geográfico y por las diferencias etnoculturales entre la población.

John Tutino (1990), por otra parte, rastrea las bases sociales de la violencia agraria desde 1750 hasta 1940. Él opina que la fragmentación de la élite y la expansión del capitalismo comercial fueron secundarias en la insurrección campesina, más bien apela a la acumulación de resentimientos producido por la pérdida de autonomía, ${ }^{6}$ falta de seguridad ${ }^{7}$ y movilidad. $^{8}$ Alan Knight (1996), comparte la perspectiva de Tutino, al decir que los campesinos se rebelaron durante la Revolución mexicana porque contaban con estructuras formales corporativas como propiedad comunal de la tierra, jerarquías civiles y religiosas, cofradías, organizaciones de barrios; junto a los liderazgos tradicionales y la solidaridad informal dentro de la sociedad campesina, producto de la lógica de la agricultura de subsistencia.

Knight (1996) en el punto de seguridad refuta a Tutino (1990), al sostener que los peones de las haciendas no pudieron rebelarse, porque estaban sometidos a un rígido sistema de vigilancia y represión. Pero Joseph (2002), expresa que los peones manifestaron su descontento a través de la quema de cultivos, suicidio, embriaguez y la realización de las actividades de mala gana. En general, Knight (1996), Tutino (1990) y Joseph (2002) recurren a las teorías de movilización de recursos y oportunidades políticas para explicar la insurrección de los campesinos en el México de los siglos XIX y XX.

La reactivación de las revueltas campesinas y, el impacto de la creciente agricultura de temporal en las décadas de 1960 y 1970 en México abrieron diferentes perspectivas de análisis. El marxismo estructural (Zepeda, 1988, p. 16), propició dos tendencias: el campesinista ${ }^{9}$ defendida por Canales (1988) y Warman (1976) y, la descampesinista encabezada por Bartra (1979). ${ }^{10}$ El debate entre campesinistas y descampesinistas sobre la orientación del proceso de desarrollo de la agricultura muestra una diversidad ideológica. Unos defienden la vía capitalista, otros destacan la necesidad de una vía no capitalista o campesina. A pesar de las diferencias entre los dos grupos mencionados, se puede incluir a la mayoría de los autores en la corriente ideológica del materialismo histórico (Heynig, 1982, p. 136)

Ambas corrientes de pensamiento sumieron las discusiones en un atolladero intelectual. Para superar esa ambivalencia, como bisagra entre una vieja discusión y una novedosa que se avizoraba, apareció el trabajo dirigido por Gustavo Esteva (1980), más que una investigación es una apretada síntesis de los conflictos y problemas que enfrentaba el agro mexicano desde 1917 hasta 1970. Existen tintes de campesinismo en el trabajo, sin embargo, por ser un balance general de la

\footnotetext{
${ }^{6}$ Se define como la capacidad de la gente para producir en forma independiente lo que necesitaba para subsistir. El campesino era el más autónomo del campo, pues producía la mayoría de los bienes para su subsistencia. La autonomía del granjero era reducida: si bien controlaba su producción dependía de los mercados para vender su producción y obtener bienes esenciales. Los jornaleros eran los menos autónomos del agro, no controlaban la producción.

${ }^{7}$ La seguridad se entiende como la capacidad de alcanzar la subsistencia de modo uniforme: de confiar en un mínimo aceptable en nivel de vida a lo largo de un futuro predecible. Entre los campesinos la seguridad cambia según la región y la calidad de las tierras, y las condiciones de acceso a la tierra, regularidad de las lluvias; jornaleros según disponibilidad de trabajadores, su calificación y organización. La seguridad del ranchero se mide en función de producción de las tierras, las deudas, cosechas y condiciones del mercado.

${ }^{8}$ Se refiere a que la gente tenga opciones dentro de un modo de vida en vigor.

${ }^{9}$ Ésta corriente considera que la agricultura comercial explota a un sector numeroso de minifundistas, se apropia de los excedentes de sus parcelas o bien los explota como mano de obra barata. Por lo tanto, la producción familiar permanece y se fortalece, ya que trabajan la parcela y se emplean en la agricultura comercial.

10La postura descampesinista encabezada por Roger Bartra, retomando la tesis leninista de descomposición del campesinado, plantea que los minifundistas en vías de desaparición o extinción supone su transformación en asalariados sin tierra.
} 
situación del campo no produjo polémica. Muchas preocupaciones delineadas serían retomadas con peculiar interés en los siguientes años.

La década de 1980 trajo consigo un conjunto de estudios y preocupaciones sobre el campo. Además del interés académico, la crisis comenzó a pegar fuerte, siendo el campo el más afectado del sistema. La pérdida de autosuficiencia alimentaria fue el elemento detonante para enrumbar la investigación por otras vías. La pregunta fue menos la naturaleza del campesino y más el intento por responder que era la sociedad rural, sus actores y su papel tan comprometido para con el resto de la sociedad. Parte de la producción intelectual estuvo orientado a encontrar las causas de la crisis y su posible salida. Un común denominador de estos trabajos es la preocupación por la incapacidad del campo mexicano para seguir alimentado a la población (Zepeda, 1988, p. 20).

Bajo el anterior contexto, proliferaron productos intelectuales, que tenían como preocupaciones analizar los movimientos campesinos en el agro mexicano. Algunos, como Beatriz Caníbal Cristiani (1984) Armando Bartra (1985) y Graciela Flores Lúa, Luisa Paré y Sergio Sarmiento (1988), ofrecen un panorama global de la situación de los movimientos campesinos desde la década de 1920 hasta 1983. Esas expresiones se traducen como forma de contestación constante y permanente frente a un conjunto de factores, ya sean de crisis agrícola, represión, institucionalización agraria e introducción de la agricultura comercial. No existía, descanso para los campesinos, quienes desde la Revolución participaron con ahínco, después lo hicieron mediante la rebelión cristera, y así sucesivamente pasando por el sinarquismo hasta llegar con la movilización generalizada en toda la década de 1970.

Por último, el libro de Florencia Mallon (2003), Campesino y nación, donde argumenta que en la construcción del estado-nación jugaron un preponderante papel los campesinos de Puebla y Morelos (México), y los de Junín y Cajamarca (Perú). Desde el modelo tridimensional (comunal, regional y nacional) Mallon analiza de manera coaligada los discursos y la lucha política. Bajo esa postura, el nacionalismo para ella, en cada caso se convierte en una serie de discursos en constante formación y negociación, compitiendo entre sí sobre un campo delimitado por la historia particular del poder regional. Mallon incluye en su análisis la categoría de hegemonía entendida a partir de dos definiciones: por un lado, la entiende como una serie de procesos sociales, contiguamente entrelazados, a través de los cuales se legitima, redefine y disputa el poder y el significado a todos los niveles de la sociedad; por otra parte, como punto de llegada, donde las fuerzas en pugna pueden llegar a un acuerdo, a un equilibrio siempre dinámico o precario (Mallon, 2003, p. 85-86).

Mallon (2003) sugiriere que, para realizar una historia política desde una perspectiva subalterna, debe tomarse en serio la historia intelectual de la acción campesina. Lo cual implica derrumbar la barrera artificial entre el analista/intelectual y el campesino/sujeto y comprender el análisis como un diálogo entre intelectuales. A su vez, repensar el concepto de comunidad rural como una asociación política formada a través de procesos de creación e imaginación políticocultural.

\section{Movimientos campesinos, guerrilla y vida rural en Sinaloa}

Sobre los movimientos sociales, trabajadores rurales y revolución en Sinaloa, existen diferentes ensayos, artículos, monografías y, tesis de licenciatura y maestría producidas por el Instituto de Investigaciones de Ciencias y Humanidades -luego Instituto de Investigación Económicas y Sociales-, de la Escuela de Economía y de la Facultad de Historia de la Universidad Autónoma de Sinaloa.

En la década de 1970 y 1980 surgieron dos corrientes historiográficas. Una tendencia (Monjaraz, 1997; Villegas, 2000; Lazcano, 2001; García y Gutiérrez, 2004) de sesgo marxista-leninista planteaba que los campesinos, los trabajadores de los ingenios azucareros y el magisterio se movilizaron, gracias a los liderazgos carismáticos emanados del Partido Comunista Mexicano (PCM), que buscaban el derrocamiento del gobernador de Sinaloa Alfredo Delgado (1937-1939). Otros estudios (Ramírez, 1987, 1992, 1996; y Gómez, 1989) proponían que la proliferación de comités agrarios - que enfrentaron violentamente a los pequeños y grandes propietarios de la región- en el sur de Sinaloa, tuvieron conexión directa con la presencia de corrientes moronistas, 
lombardismo y anarquismo, en los años veinte, sobre todo en el puerto de Mazatlán. Otra postura (Padilla, 1993, 1993; Rubio, 1979; Peregrina, 1965; Hernández, Juárez, Alonso, 2003; Zavala, 2000) profundizaban en el cardenismo, explicando que desde el sur de Sinaloa se consolidó un poderoso grupo encabezado por el coronel Rodolfo T. Loaiza y sus allegados los coroneles Alfredo Delgado y Gabriel Leyva, quienes para golpear a la oligarquía callista lanzaron en su contra a los agraristas, que invadieron sus tierras con armas en mano. Con el advenimiento del gobierno de Manuel Ávila Camacho (1940-1946), la oligarquía mazatleca se recuperó y comenzó la cacería en contra de los agraristas. Para esta visión, los campesinos no tenían vida propia, dependían ideológicamente de los liderazgos políticos loaicistas.

Un numeroso grupo de académicos (Posadas, 1978; Terán, 2006; Rubio e Hirata, 1985; Hirata, Rubio, Meza, 1978; Quevedo, 1996; Meza, 2002; Delgado y García, 1980; De la Herrán,1980; Anónimo, 1980), desde el enfoque descampesinista sostenían que las movilizaciones campesinas de 1971 a 1977 fueron provocadas por la combinación de los siguientes factores: la existencia masiva de campesinos y jornaleros agrícolas sin tierra; la crisis rural que deterioró las condiciones de vida del campesino; la humillación, la miseria, la explotación, y el incumplimiento de las resoluciones presidenciales; la concentración de la tierra en manos de grandes latifundistas; los vínculos y solidaridades de los ejidatarios con los movimientos estudiantiles. Según esa visión, los actores al carecer de una conciencia de clase (interés solo por obtener tierras), los colocó en desventaja frente a una oligarquía agraria aglutinada en sólidas organizaciones nacionales y regionales.

Otros descampesinistas (López, 1991; Meza, 1989; Posadas, 1980, 1983, 1985, 1989; Guerra, 1998; Airola, 1989), argumentaban que el campesinado sinaloense se proletarizó porque perdió sus tierras, aunado a la crisis rural que deterioró sus condiciones de vida, así como el incumplimiento de las resoluciones presidenciales y, concentración de la tierra en manos de grandes latifundistas. Estas condiciones estructurales y la falta de conciencia de clase (interés sólo por obtener un predio de terreno) los colocó en desventaja frente a la burguesía ${ }^{11}$ que poseía las mejores tierras y, además porque estos fueron beneficiados con la incentivación de la investigación y la irrigación y, con la introducción de las disposiciones de inafectabilidad ganadera y agrícola en el artículo 27 constitucional, lo cual protegía sus propiedades de cualquier invasión. Todo esto produjo concentración de tierras en algunas cuantas manos y como derivación surgió el proletariado rural, ${ }^{12}$ que pronto se constituyó en clase social (trabajadores permanentes o temporarios). Ese fenómeno a largo plazo, aunado al recorte presupuestal para producción del campo originó la crisis alimentaria en 1980, que orilló al gobierno importar granos.

Ya sea como actores o estudiosos, la mayoría de los descampesinistas colocándose de parte de los obreros y campesinos, por un lado, plantearon como tesis central destruir el sistema capitalista e instaurar el socialismo como mecanismo para terminar con las contradicciones entre explotadores y explotados; por otra parte, postularon que, para mejorar las condiciones de vida de los campesinos, estos necesitaban agruparse en organizaciones sindicales autónomas y al mismo tiempo debían crear un Consejo Administrativo, aunado a la nacionalización de los modos de producción y de la tierra con el fin de mejorar el mercado interno frente al externo.

Hubo estudiosos que siguieron fielmente la escuela descampesinista, sin embargo, en los primeros años del siglo XXI, se abrieron a las teorías de los nuevos movimientos sociales y a la movilización de recursos que pregonaba la Sociología de la acción. Uno de esos autores fue Florencio Posadas

\footnotetext{
${ }^{11}$ Empíricamente y retomando a Roger Bartra, Posadas define y clasifica a la burguesía rural de la siguiente manera: la burguesía agrocomercial, que su capital lo obtuvo del comercio y la industria; burguesía agroindustrial, similar, pero ligado a lo comercial solamente; la mediana burguesía, nacida de la reforma cardenista, proveniente de fracciones de antiguos campesinos acomodados ubicados en las zonas de distritos de riego.

12 Posadas define campesinos, como las personas que no compran ni venden fuerza de trabajo, rara vez lo hacían, si era necesario, subsistían de la producción mercantilizadora y del autoconsumo. El proletariado rural se componía de trabajadores sin ninguna propiedad y de asalariados que poseían algunas tierras (ejidos) donde residían y complementaban su sueldo.
} 
(2005), quien utilizando las categorías de análisis estructura, ${ }^{13}$ subjetividad, ${ }^{14}$ identidad, ${ }^{15}$ voluntad colectiva ${ }^{16}$ y movimiento social, ${ }^{17}$ realizó una comparación entre dos regiones: el valle de Culiacán y el valle de San Quintín, en Baja California Norte. Posas realizó un exhaustivo trabajo de campo, especialmente entrevistas, recogió testimonios de líderes sindicales, agroindustriales y funcionarios agrarios. Termina diciendo el autor que los emigrantes fueron los configuradores de un fuerte movimiento social en los valles sinaloenses y bajacalifornianos.

En las décadas de 1990 y 2000, desde la teoría de la movilización de recursos y de la historia social inglesa (Thompson, 1989), una corriente (Cázares Aboytes, 2005a y 2005b; Fuentes, 2005; Ramírez, 1987; Norzagaray, 1998) esgrime que, en la segunda mitad del siglo XIX, los hacendados y las compañías deslindadoras despojaron de sus tierras a los indígenas, quienes se vieron orillados a emplearse en el ingenio United Sugar Company (USCO) donde fueron sometidos a explotación. Según esta corriente, los indígenas convertidos en clase obrera con la Revolución mexicana tomaron conciencia de clase, lo cual se tradujo en organización y estallidos de huelgas, pero su punto organizativo más álgido lo alcanzaron durante el cardenismo (1934-1939), momento cuando los obreros pidieron dotación de tierras, cuyo resultado fue la construcción de la Sociedad de Interés Colectivo Agrícola (SICAE) (Gil, 1983; Gastélum y Villela, 1979; García y Cruz, 1979; Millán, 1989; Gómez, 1985; Echevarría, 2000; Schubert, 1998). Esa agrupación pronto adquirió mucho poder, al grado de colocar a varios de sus miembros en alcaldías, diputaciones y senadurías, y su declive se dio por los conflictos internos y por los enfrentamientos con el gobierno de Miguel Alemán. La misma ruta siguieron, los sindicatos de Navolato y El Dorado, de conflictos y pugnas internas derivaron en la conformación de comités agrarios, que demandaron la entrega de tierras. A partir de 2004 al 2013, en Sinaloa surgieron nuevas tendencias de análisis. Una corriente (Santos, 2007; Perea, 2009; Soto, 2011), dominado por las teorías sociológicas de la identidad, agravio moral, la acción colectiva, la movilización de recursos y la oportunidad política (Torrow, 1997; Melucci, 1999; Bolos, 1999; Tilly, Tilly y Tilly, 1997), proponía que los movimientos campesinos y las guerrillas urbanas surgieron por la imbricación de los siguientes elementos: proletarización campesina, perdida de tierras, centralización y deslegitimación del poder político, liderazgos carismáticos, la capacidad organizativa, estructuras culturales, la ideología, el discurso político, las sociabilidades, resultados estratégicos (violencia, miedo, coacción, actitudes mentales místicos, recuerdos históricos mitificados y visiones utópicas futuristas), la solidaridad, identidades colectivas y grupales, y fractura entre las élites.

Otra línea de análisis (Sánchez, 2011, 2012, 2013a, 2013b), que parte del estructuralismo y de la historia cultural (Chartier, 1992), explica que los estudiantes universitarios sinaloenses optaron por la vía armada motivados por múltiples factores y causas como agotamiento de desarrollo estabilizador mexicano, crisis económica de 1970, régimen autoritario del sistema político, la influencia de la Revolución cubana, y la sociabilidad y la red de asociaciones estudiantiles dentro de la Universidad Autónoma de Sinaloa. Además, esa misma corriente agrega que la politización de los estudiantes se debió a la pedagogía de la prensa universitaria, la difusión cultural revolucionaria promovida por Radio UAS, Librería Universitaria y los planes y programas de estudios.

\footnotetext{
${ }^{13}$ Se refiere a las relaciones sociales, la cultura y a la personalidad.

${ }^{14}$ Ese concepto implica que los actores movilizados con las utopías y e imaginarios pueden interpretar y reinterpretar las condiciones económicas, políticas y sociales. En ese sentido, los trabajadores asalariados desataron una lucha de clases contra la burguesía agraria.

${ }^{15}$ Según Posadas, la identidad de los actores, construye con base a la organización sindical, demandas étnicas (respeto a los derechos culturales de los indígenas), peticiones agrarias y campesinas (como tierras, crédito y mejores precios). Las diferencias pueden surgir únicamente cuando los movilizados no son todos beneficiados.

${ }^{16}$ Se entiende como la compleja red de prácticas de los diferentes miembros de una misma clase o grupo social en función de un fin compartido que siempre es de largo alcance.

17 Significa una reacción de agravio colectivo provocado por una injusticia evidente y una acción flagrante e ilegítima del adversario. Para el autor, un movimiento social explota porque se combinan los siguientes factores: la concentración de obreros agrícolas e indígenas en espacios y franjas reducidas de campamentos y colonias habitacionales; la comunicación como forma de difusión del movimiento, al no darse se quedaría en ira individual; la organización, no necesariamente anterior, sino posterior como vía de interacción colectiva de los fenómenos que se nutren de influencias, ficciones, maniqueísmos, que conducen a la identificación de enemigos y al proceso de impacto del movimiento sobre la identidad.
} 
Una última tendencia (Santos, 2013), retomando la categoría analítica de hegemonía de Mallon y aludiendo al gran arco de la Revolución mexicana, plantea que los liderazgos políticos y dirigentes populares desde 1910 a 1940 se sostuvieron en el poder político estatal y municipal gracias a toda una red de agrupaciones obreras y campesinas que los respaldaban. En contrapunto, ésta corriente también estudia los liderazgos políticos y populares de oposición como el general Ángel Flores y las filiales de la Central de Trabajadores de México, que disputaron y negociaron el poder con el bloque hegemónico. Durante el periodo mencionado, la masiva movilización de campesinos y de los sectores populares sirvió para moldear la formación del Estado nacional. De 1941 a 1969, fue diferente ya que se había agotado el Estado revolucionario, ahora los liderazgos agrarios ya no se movían dentro de los espacios del poder, por el contrario combatían abiertamente al Estado. Se le puede llamar la fractura del gran arco de la Revolución mexicana, ya que el sistema político mexicano, se vio estremecido por una gama de movimientos sociales.

Sobre los últimos años, en otras partes de México la discusión sobre movimientos sociales y guerrillas urbanas, al parecer sigue la misma tendencia que Sinaloa. Por ejemplo, en Guadalajara, Monterrey y México para estudiar el surgimiento de la Liga Comunista 23 de septiembre (LC23S) (Gamiño y Toledo, 2011; Escamilla, 2013), se recurría a la teoría de movilización de recursos, oportunidades políticas y a la visión estructural. El mismo Escamilla hizo una prosopografía de los militantes de la LC23S, destacando su perfil estudiantil-urbano, al mismo tiempo decía que lo más destacado de la Liga fue la educación y la agitación política, especialmente después de 1976 (Escamilla, 2017, p. 173).

Desde las memorias subalternas contrahegemónicas, el historiador Gamiño, estudia la memoria como complementariedad, bajo el enfoque de las Iniciativas no Oficiales de Memoria (INOM). Centra su mirada en las acciones políticas y los mecanismos de resistencia desarrollados por actores que estaban insatisfechos con las decisiones tomadas unilateralmente por el Estado, a través de los mecanismos oficiales en torno al pasado. Estos actores que eran víctimas, como dice el autor son espontaneas, transitorias, huérfanas de apoyo oficial y carentes de recursos económicos (Gamiño, 2013, p. 24-25).

\section{La historia económica: entre lo cuantitativo, la narración y las redes}

Sobre la historia económica en Sinaloa mucha investigación se ha publicado. Los académicos más prolíficos se formaron en la década de 1980, especialmente en la Escuela de Economía de la Universidad Autónoma de Sinaloa, posteriormente estudiaron maestría en la Facultad de Historia y el doctorado en el Instituto de Investigaciones de Ciencias Sociales y Humanidades de la misma Universidad. Como resultado de ese proceso, en la UAS se consolidó una corriente de historia económica que sigue teniendo fuerza hasta hoy en día, aunque también existen otras líneas de investigación como la historia sociocultural y política.

En la década de 1990 y 2000, tres grandes corrientes historiográficas han predominado en Sinaloa. Un enfoque (Cartón, 1990), desde conceptos marxistas, sostiene que en el agro sinaloense en la década de 1930, la burguesía agraria al organizarse en distintivos niveles pudo conformarse en una sólida clase social, ${ }^{18}$ con intereses propios y bien definido frente al Estado. En contraparte la clase social campesina se definía a partir del trabajo propio y familiar, que buscaba, no la ganancia, sino la producción de la familia.

La teoría de redes (Aguilar, 2000, 2003; Martínez, 2004; Brito, 2005; Ojeda y Jiménez, 2005; Burgos, 2003), en cambio defiende que la Revolución mexicana llevó al poder político y económico a una nueva élite, que en vez de destruir a la oligarquía porfirista se convirtió en su fiel defensora. E incluso en la posrevolución, la vieja élite agroindustrial para fortalecerse trabó alianzas

\footnotetext{
${ }^{18}$ Con base a los procesos de acumulación y los procesos de organización se define la burguesía en una clase social. La actividad agrícola tiene las siguientes bases de acumulación: primero, ganancia como resultado de la inversión del capital en un proceso de producción concreto, como el cultivo de caña de azúcar y hortalizas hasta el cardenismo; segundo, renta diferencial resultado de la ubicación de la burguesía en tierras de riego y los cultivos de exportación; tercero, canalización de las ganancias del campo hacia la banca, con lo cual fue rebasado la agricultura para ubicarse en la agroindustria, el comercio, la industria y el turismo.
} 
matrimoniales y de compadrazgos con la élite gobernante, a su vez incursionó en espacios de decisión política. De esta manera, la élite de agricultores siguió vigente, con menos extensión territorial en su poder, pero aun así conservaba magnitudes considerables de terrenos; gozaban de concesiones de agua que revaloraban sus tierras y elevaban su productividad; controlaban las organizaciones de agricultores y de recursos financieros; se habían convertido en un grupo de presión con fuerte presencia económica y política y reafirmaban todas estas ventajas con frecuentes desplazamientos a la esfera de los cargos públicos. Según esa visión (Aguilar, 1998; Martínez, 1997; Ibarra, 2003; Rivera, 2001), a pesar de que le élite porfirista sufrió serios embates de la élite nacional gobernante y de los segmentos de campesinos y obreros durante el cardenismo (1934-1940), siguió siendo un grupo privilegiado.

En Sinaloa, durante la década de 2000, se consolidó una corriente que siguió los enfoques y teorías institucionales (Caballero, 2004; Oriol, 2007), sobre todo los planteados por Douglass North, quien postulaba que las instituciones ${ }^{19}$ corresponden a los factores formales e informales condicionantes de creación de empresas y las organizaciones que tendrán mayor interés serán las empresas y los empresarios que las dirigen, influyendo en el crecimiento y desarrollo económico de un país o región. También son relevantes otras organizaciones y sus agentes relacionados directa o indirectamente con la creación de la empresa, tales como los organismos de asistencia al nuevo empresario (administraciones o asociaciones de empresarios, sindicatos, patronales y universidades (Pulido, Díaz y Hernández, 2005, p. 5).

La historia económica desde el institucionalismo, en Sinaloa se configuró alrededor de un grupo de profesores que tuvieron la formación de licenciatura en Economía, con posgrados en Historia y en Ciencias Sociales (Cerutti, 2000; Aguilar, 1993, 2003, 2008; Padilla, 1996; Frías, 2008; López López, 2013; Carrillo, Padilla, Aguilar, Brito y Martínez 1994; Chávez, 2007; Huerta, 1991; Ibarra, 1993; Rivera, 2001; Román, 2006; Verdugo, 1987). Entre los más destacados figuran el Dr. Mario Cerutti (cabeza del grupo en la región, aunque su adscripción pertenece a la Universidad Autónoma de Nuevo León), Arturo Carrillo, Gustavo Aguilar, Eduardo Frías y otros tantos formados en la licenciatura en Historia.

Estos investigadores para realizar sus análisis parten del método cuantitativo, destacando estadísticas de inversión y producción, así como las cifras sobre ganancias, créditos y préstamos bancarios, exportaciones e importaciones. Todos estos estudiosos coinciden en que la agricultura empresarial sinaloense prosperó durante la etapa del desarrollo estabilizador, favorecido por la interrelación de los siguientes factores: la conservación de nichos productivos y, las alianzas entre los propietarios sinaloenses y los dirigentes políticos nacionales en la etapa precardenista; expedición de títulos de inafectabilidad en 1942, 1947 y 1948; creación de obras de infraestructura hidráulica (presas y canales de riego); demanda de productos agrícolas en el mercado externo, especialmente en Estado Unidos; iniciación de la apertura de líneas crediticias atractivas para el sector privado; diseños estratégicos para obtener maquinaria, semillas mejoradas y agroquímicos en Estados Unidos y Europa; derechos de propiedad, regulación económica y capacidad empresarial.

A finales de la década de 2000, y durante los primeros años de la década de 1910, los maestros y sus discípulos siguieron cultivando la historia económica, desde los ejes temáticos institucionales como el desarrollo agroindustrial, familias, créditos, agrupaciones empresariales, el agua como elemento de disputa entre los grandes y pequeños empresarios (Román, 2009; Frías, 2009; Carrillo y Rodríguez, 2009; Sosa, 2015). Desde la Ciencias Política surgió una corriente (Moya, 2013), que estudia la consolidación de la élite en Sinaloa desde 1940 hasta 1910. La tesis central es que la democracia representativa no ha funcionado, porque existen grupos y familias arraigados al poder con intereses propios.

$\mathrm{Al}$ voltear la mirada hacia Guadalajara, es fácil distinguir dos tendencias muy claramente. Una corriente historiográfica (Valerio, 2012), desde la teoría de la narración de Ricoeur, relata un

${ }^{19}$ Se entiende como normas y reglas restrictivas que rigen en la sociedad, condicionando y dirigiendo el marco de relaciones que se producen en ella. 
discurso histórico de tres haciendas que durante la segunda mitad del siglo XIX y las primeras décadas del XX constituyeron un gran latifundio: Bellavista, El Plan y Las Navajas. Según esta visión, la trama de la historia inicia a finales del siglo XVI, y finaliza en los años treinta del siglo $\mathrm{XX}$; en medio de estos dos límites temporales se desarrollan las acciones humanas de los hombres y mujeres que vivieron, habitaron y trabajaron en las haciendas.

Otra línea de investigación muy trabajada ha sido el concepto de red, que los estudiosos utilizan para analizar las relaciones y vínculos de los empresarios de Guadalajara, de Mazatlán y Tepic. Han destacado tres tipos de red: red familiar, uno de los más intensos y duraderos; red empresarial, la cual cada empresario se relaciona con otros empresarios de las compañías que forman y de las cuales son socios; la red de crédito, en la cual se vinculan los actores económicos como acreedores o deudores, por medio del cual fluyen los capitales de unas manos a otras (Lizama y Valerio, 2012; Cerutti, 2006; Valerio, 2008).

\section{Conclusión}

La producción de textos sobre revoluciones, movimientos sociales, revueltas rurales, guerrillas, empresas y empresarios se movieron bajo un contexto sociopolítico. Durante las décadas de 1960, 1970 y 1980, fue la época de la guerra fría, el enfrentamiento del proyecto capitalista contra el socialismo. En ese contexto surgieron movimientos estudiantiles mundiales, la guerra de Vietnam que no cesaba, la Revolución cubana que se convirtió en un faro que iluminó la esperanza los jóvenes latinoamericanos. En México, estalló el movimiento estudiantil de 1968, la represión sistemática produjo el nacimiento de guerrilleras urbanas y rurales en diferentes regiones del país; los movimientos campesinos brotaron por doquier, invadían propiedades de ricos empresarios, al tiempo que se enfrentaban con las fuerzas represivas del Estado.

En 1965, los estudiantes sinaloenses también se rebelaron tomaron por asalto la Universidad Autónoma de Sinaloa y el Tecnológico de Culiacán; expulsaron a la mayoría de los maestros y funcionarios universitarios. Los estudiantes inmersos en el contexto de la ideología marxistaleninista optaron por insurreccionarse contra el Estado y sus aliados los empresarios. Fue alrededor de tres décadas en que la Universidad permaneció bajos los vaivenes de la política y los choques violentos.

Al apaciguarse la situación sociopolítica en la Universidad, muchos de los actores militantes comenzaron a reflexionar, y como derivación se abocaron a escribir sobre los movimientos campesinos y estudiantiles; el análisis que hicieron fue desde marxismo-leninismo, descampesinista y campesinista. Las inquietudes e inclinaciones ideológicas de estos estudiosos, todavía pesaban, querían explicar porque había fallado o tenido éxito el movimiento - ya sea campesino o estudiantil- en los que les tocó participar.

A mediados de la década de 1980, profesores externos a la UAS con un nutrido grupo egresado de la Escuela de Economía fundaron la Maestría en Historia Regional. Al terminar la maestría fundaron la Licenciatura en Historia y, la línea de investigación predominante fue Historia Económica, los enfoques de análisis fueron red - familiar, de crédito y empresaria- e institucionalismo. Ese grupo hasta ahora en conexión con otros investigadores externos siguen produciendo historia económica desde los enfoques ya mencionados.

Durante la década de 2000, las líneas y los enfoques de investigación se diversificaron. Una corriente desde la teoría de la movilización de recursos y de la historia social inglesa trata de explicar los movimientos obreros, las revueltas campesinas y las guerrillas en Sinaloa. Esos mismos fenómenos son estudiados desde las teorías sociológicas de identidad, de la acción colectiva, y de la historia cultural. También se han investigado los cacicazgos políticos en Sinaloa, utilizando el concepto de hegemonía, lo cual permite ver la alta y baja política en un constante diálogo.

\section{Referencias bibliográficas}

Aguilar Aguilar, Gustavo (1993). La industria del azúcar. DIFOCUR, México. 
Aguilar Aguilar, Gustavo (2003). Banca y desarrollo regional en Sinaloa, 1910-1994. Universidad Autónoma de Sinaloa, DIFOCUR y Plaza y Valdez, México.

Aguilar Aguilar, Gustavo (2008). Inmigración griega. Creación de empresas y actividad empresarial en Sinaloa (siglo XX). Instituto Sinaloense de la Cultura, México.

Aguilar Aguilar, Gustavo y Frías Sarmiento, Eduardo (2009). En Gustavo Aguilar Aguilar y Eduardo Frías Sarmiento (coordinadores). Historia de empresarios y grupos de poder en Sinaloa: del porfiriato al salinismo. Universidad Autónoma de Sinaloa. México.

Aguilar Alvarado, Modesto (2000). Agua y Poder del canal Rosales a la construcción de la presa Sanalona. Archivo Histórico General del Estado de Sinaloa-La Mariposa Amarilla. México.

Aguilar Alvarado, Modesto (2003). Los grandes agricultores del valle de Culiacán. Dirección de Investigación y Fomento de Cultura Regional, México.

Aguilar Soto, Cesar (2010) Empresarios y desarrollo agro comercial en Sinaloa. Universidad Autónoma de Sinaloa y Plaza y Valdés. México.

Airola, Roberto (1989). Crisis agrícola, situación actual y perspectiva del movimiento campesino en Sinaloa. Revista Ciencia y Universidad, No. 14, México (pp.115-126).

Anónimo (1980). La coyuntura en la agricultura sinaloense. Revista Ciencia y Universidad. No. 12, México (pp: 32-40).

Bartra, Armando (1985). Los herederos de Zapata. Movimientos campesinos posrevolucionarios en México. Ediciones Era, México.

Bartra, Roger (1979). Estructura agraria y clases sociales en México. Ediciones Era. México.

Bolos, Silvia (1999). La constitución de los actores sociales y la política. Universidad Iberoamericana. México.

Brito Rodríguez, Félix (2005). Dinámica sociopolítica en el Sinaloa posrevolucionario: entre familias, redes $\mathbf{y}$ actores. Tesis de Doctorado en Ciencias Sociales. Centro de Investigaciones y Estudios Superiores en Antropología Social-Occidente. México.

Burgos Aguilar, Diana Sugey (2003). La Familia Clouthier: parte de la elite culiacanense. Su trayectoria en los años de 1920-1050. Tesis de Maestría en Historia. Universidad Autónoma de Sinaloa, México.

Caballero, Gonzalo (2004). Instituciones e historia económica: enfoques y teorías institucionales. Revista de Economía Institucional. No. 10. México, (pp. 135-157).

Canales, Alejandro (1988). El agro mexicano: viejas y nuevas polémicas. En Jorge Zepeda Patterson (1988). (Editor). Las sociedades rurales hoy. EL colegio de MichoacánCONACYT. México.

Caníbal Cristiani, Beatriz (1984). Hoy luchamos por la tierra. Universidad Autónoma Metropolitana-Xochimilico. México.

Carrillo Rojas, Arturo y Rodríguez Quintero, Lilia (2009). La familia Podesta y la historia de su actividad empresarial agrícola. En Gustavo Aguilar Aguilar y Eduardo Frías Sarmiento (coordinadores), Historia de empresarios y grupos de poder en Sinaloa: del porfiriato al salinismo. Universidad Autónoma de Sinaloa, México.

Carrillo Rojas, Arturo; Padilla Beltrán, Francisco; Aguilar, Gustavo; Brito Rodríguez, Félix; y Martínez Barreda, Alonso (1994). Historia de los empresarios agrícolas en Sinaloa, 1880-1920. DIFOCUR. México.

Cartón de Grammont, Hubert (1990). Los empresarios agrícolas y el Estado. UNAM. México. Cázares Aboytes, Pedro (2005a). El movimiento obrero-campesino en la United Sugar Companies: 1903-1939. Tesis de Maestría en Historia. Universidad Autónoma de Sinaloa, México.

Cázares Aboytes, Pedro (2005b). La propiedad de la tierra y su evolución en el norte de Sinaloa: El caso de El Fuerte". Revista Clío, No. 33, México. (pp. 45-66).

Cerutti, Mario (2000). Propietarios, empresarios y empresa en el norte de México. Siglo XXI. México. 
Cerutti, Mario y Carrillo Rojas, Arturo (2006) (Coordinadores). Agricultura comercial. Empresa y desarrollo regional en el noroeste de México, Universidad Autónoma de Nuevo León, UAS y Consejo Nacional de Ciencia y Tecnología, México.

Chartier, Roger (1992). El mundo como representación. Historia cultural: entre práctica y representación. Gedisa, España.

Chávez Ojeda, Ofelia (2007). Empresas y empresarios agrícolas en el Valle de Culiacán, 19301950. Tesis de Maestría en Historia. Universidad Autónoma de Sinaloa. México.

De la Herrán García, Jorge (1980). La migración campesina en Sinaloa. Revista Ciencia y Universidad. No, 13, México (pp. 77-102).

Delgado Cortés, Jorge y Benito García (1980). Registro cronológico de las luchas de los obreros agrícolas migratorios en Sinaloa. Revista Ciencia y Universidad. No. 13, México (3240).

Echevarria, Esperanza (2000). El Dorado. Un pueblo contra su nombre. La crónica de Culiacán. México.

Escamilla Rodríguez, José Ángel (2013). La Liga Comunista 23 de septiembre, 1973-1976. Tesis de licenciatura en Historia, Universidad Autónoma Metropolitana-Unidad Iztapalapa, México.

Escamilla Rodríguez, José Ángel (2017). Estructura social y organizativa de la Liga Comunista 23 de Septiembre: 1973-1980. Signos Históricos, Vol. XIX, No. 38, México (pp. 172-195).

Esteva, Gustavo (1980). La batalla en el México rural. Siglo XXI. México.

Flores, Graciela; Paré, Luisa y Sarmiento, Sergio (1988). Las voces del campo. Movimiento campesino y política agraria, 1976-1984. Siglo XXI, México.

Frías Sarmiento, Eduardo (2008). El oro rojo de Sinaloa. E1 desarrollo de la agricultura del tomate para la exportación, 1920-1956. Universidad de Guadalajara, UCLA Programa México, Universidad Autónoma de Sinaloa y Casa Juan Pablos. México.

Frías Sarmiento, Eduardo (2009). Empresas y actividad empresarial en la producción de tomate sinaloense: 1920-1956. En Gustavo Aguilar Aguilar y Eduardo Frías Sarmiento (coordinadores). Historia de empresarios y grupos de poder en Sinaloa: del porfiriato al salinismo. Universidad Autónoma de Sinaloa. México.

Fuentes Posadas, Javier (2005). Una rebelión indígena al amparo de la revolución: Felipe Bachomo y los mayos, 1913-1916. Tesis de Maestría en Historia. Universidad Autónoma de Sinaloa. México.

Gamiño Muñoz, Rodolfo (2013). Resistir al olvido. Iniciativas no oficiales de memoria implementadas por ex militantes del movimiento armado socialista en la ciudad de México y en Guadalajara, 2000-2011. Tesis de doctorado en Antropología Social, Centro de Investigaciones y Estudios Superiores en Antropología Social, México.

Gamiño Muñoz, Rodolfo y Toledo González, Mónica Patricia (2011). Origen de la Liga Comunista 23 de septiembre. Espiral, No. 52, Vol. XVIII, México (pp. 9-36).

García Ramírez, Guadalupe y Jesús Ramón Gutiérrez (2004). Partidos políticos y movimientos sociales en Sinaloa, 1929-1940. Universidad Autónoma de Sinaloa, Consejo Estatal Electoral de Sinaloa y Publicaciones Cruz O., S. A. México.

García, Myrna y Vicente Cruz (1986). La SICAE en el movimiento obrero y campesino en el norte de Sinaloa, 1939-1959. UNAM, Tesis de licenciatura en Ciencias Políticas, México.

Gastélum S., Silvia y Samuel Villela Flores (1979). Acumulación originaria, lucha proletaria y colectivización ejidal en Sinaloa. El caso de la SICAE. Revista Ciencia y Universidad, No. 37, México (pp.43-74).

Gil, Mario (1983). La conquista del Valle del Fuerte. DIFOCUR, México.

Gómez Quiñones, Hugo Federico (1985). Las luchas sindicales en el Ingenio de El Dorado (19301942). Revista Ciencia y Universidad. No. 10-11, México (pp.21-43).

Gómez Quiñones, Hugo Federico (1989). La Federación de Trabajadores de Sinaloa y sus antecedentes. Revista Ciencia y Universidad. No. 14, México (pp. 143-171). 
Guerra Ochoa, María Teresa (1998). Los trabajadores del campo en el valle de Culiacán. En Guillermo Ibarra y Ana Luz Ruelas (Compiladores). Contribuciones a la Historia del Noroccidente Mexicano. Memoria del VIII Congreso Nacional de Historia Regional. Universidad Autónoma de Sinaloa. México.

Hart, John M. (2004). La guerra de los campesinos del suroeste mexicano en los años 1840: conflicto en una sociedad transicional. Friedrich Katz (compilador). Revuelta, rebelión y revolución. La lucha rural en México del siglo XVI al siglo XX. Ediciones Era. México.

Hernández, Iván; Juárez, Miguel A.; Alonso Rivera, Miguel (2003). Grandes Crímenes del siglo, en Guillermo Ibarra Escobar y Arturo Carrillo Rojas (Coordinadores), Sinaloa 100 años. Al gran aventura del siglo XX. Universidad Autónoma de Sinaloa y Periódico Noroeste, México.

Heynig, Klaus (1982). Principales enfoques sobre la economía campesina. Revista de la CEPAL. No. 16, Santiago de Chile (pp. 116-142).

Hirata, Jaime F.; Rubio, Baldemar; Meza, Heriberto (1978). 1976: las invasiones de tierra en Sinaloa. Universidad Autónoma de Sinaloa, México.

Huerta Sandoval, Armando (1991). Factores que generalizaron la agricultura empresarial en los valles de Sinaloa (1940-1960)". VII Congreso de Historia Regional. Universidad Autónoma de Sinaloa. México.

Ibarra Escobar, Guillermo (2003). Sinaloa en el periodo de los caudillos. Política y economía en la década de los veinte". Guillermo Ibarra Escobar y Arturo Carrillo Rojas (Coordinadores). Sinaloa 100 años. La gran aventura del siglo XX. Universidad Autónoma de Sinaloa/Periódico Noroeste. México.

Ibarra, Guillermo (1993). Sinaloa tres siglos de economía. De la minería a los servicios. Dirección de Investigación y Fomento de la Cultura Regional, México.

Joseph, Gilbert M. (2002). Para repensar la movilización revolucionaria en México: Las temporadas de turbulencia en Yucatán, 1909-1915. Joseph, Gilbert M. y Daniel Nugent (coordinadores). Aspectos cotidianos de la formación del Estado. Edición Era. México.

Katz, Friedrich (2004). Las rebeliones rurales en el México precortesiano y colonial. En Friedrich Katz. Revuelta, rebelión y revolución. La lucha rural en México del siglo XVI al siglo XXI. Ediciones Era. México.

Knight, Alan (1996). La revolución mexicana, tomo I. Grijalbo. México.

Lazcano Ochoa, Jesús (2001). La Universidad Socialista del Noroeste. Documentos, relatos y opiniones. Universidad Autónoma de Sinaloa. México.

Lizama Silva, Gladys y Sergio Valerio Ulloa (2006). Cántabros entre Guadalajara, Tepic y Mazatlán. Élite, redes y empresariales. Rafael Domínguez Martín y Mario Cerutti Pignat (editores). De la colonia a la globalización. Empresarios cántabros en México. Universidad de Guadalajara. México.

López Álvarez, Manuel (1991). La demanda por la tierra en el valle de Culiacán en los años de la contrarreforma agraria (1940-1958). VII Congreso de Historia Regional. Universidad Autónoma de Sinaloa. México.

López López, María de Jesús (2013). Agricultura comercial, creación de empresas y actividad empresarial en el Valle de Culiacán, 1948-1970. Universidad Autónoma de Sinaloa. México.

Mallon, Florencia E (2003). Campesinos y Nación. La construcción de México y Perú poscoloniales. El Colegio de San Luís, El Colegio de Michoacán y El Centro de Investigaciones y Estudios Superiores en Antropología Social. México.

Martínez Barreda, Alonso (1997). De Revolucionarios a elite de poder en Sinaloa. Memoria del XI Congreso de Historia Regional. Universidad Autónoma de Sinaloa. México. 
Martínez Barreda, Alonso (2004). Relaciones de poder y políticas en Sinaloa, 1919-1920. Universidad Autónoma de Sinaloa-Colegio de Sinaloa. México.

Melucci, Alberto (1999). Acción colectiva, vida cotidiana y democracia. El Colegio de México. México.

Meza Campusano, Heriberto (1989). Necesaria distribución de la tierra para terminar con el hambre. Revista Ciencia y Universidad. No. 14, Nueva Época, México (pp. 71-77).

Meza Campusano, Heriberto (2002) (Compilador). Fragmentos de la Monografía Agraria de Sinaloa. Universidad Autónoma de Sinaloa, México.

Millán Alarid, Alfredo Octavio (1989). Historia del Sindicato de Trabajadores azucareros de Navolato SECC. 15 (1931-1950). IV Congreso de Historia regional. Universidad Autónoma de Sinaloa, México.

Monjaraz Buelna, Rodolfo (1997). Testimonio de un universitario. Universidad Autónoma de Sinaloa. México.

Moore, Barrington (1973). Los orígenes sociales de la dictadura y de la democracia. El señor y el campesino en la formación del mundo moderno. Ediciones Península, España.

Moore, Barrington (1989). La injusticia: bases sociales de la obediencia y la rebelión. Universidad Autónoma de México, México.

Moya Delgado, Octaviano (2013). La élite política en Sinaloa: conformación y permanencia, 19502010. El Colegio de Jalisco, México.

Norzagaray Gámez, Columba (1998). Liberalismo y propiedad de la tierra en Sinaloa (18701910). Tesis de Maestría en Historia. Universidad Autónoma de Sinaloa. México.

Ojeda Gastélum, Samuel y Jiménez Lauren, Rigoberto (2005). Los Peiro: Propiedad y hegemonía en el agro sinaloense. En Arturo Carrillo Rojas y Mayra Lizzete Vidales Quintero (Compiladores). Riqueza y poder. Universidad Autónoma de Sinaloa. México.

Oriol Prats, Joan (2007). Revisión crítica de los aportes del institucionalismo a la teoría y la práctica del desarrollo. Revista de Economía Institucional. No. 16, México (pp. 121-148).

Padilla, Francisco (1993). Lo que el tiempo se llevó. DIFOCUR-Universidad Autónoma de Sinaloa. México.

Padilla, Francisco (1996). Los empresarios del valle de E1 Fuerte durante el Porfiriato. Colegio de Bachilleres del Estado de Sinaloa-DIFOCUR, México.

Perea Romo, Diana M (2009). La rebelión zapatista en Sinaloa. Tesis de Maestría en Historia. Universidad Autónoma de Sinaloa. México.

Peregrina, Francisco (1965). El Sur de Sinaloa. Ed. Costa ACIC, México.

Posadas Segura, Florencio (1978). Clases sociales y conciencia campesina en el campo. Revista Ciencia y Universidad. No. 5, México (pp. 19-26).

Posadas Segura, Florencio (1980). Condiciones de trabajo y relaciones de producción de los proletarios agrícolas migratorios en Sinaloa. Revista Ciencia y Universidad. No. 13, México (pp. 41-64).

Posadas Segura, Florencio (1983). Ideología política del proletariado agrícola. Revista Ciencia y Universidad. No. 3, México (pp. 3-22).

Posadas Segura, Florencio (1985). El proletariado agrícola en el Estado de Sinaloa. Universidad Autónoma de Sinaloa. México.

Posadas Segura, Florencio (1989). Las organizaciones sociopolíticas en el campo sinaloense. Revista Ciencia y Universidad, No. 14, México (pp. 105-125).

Posadas Segura, Florencio (2005). Movimientos sociales de los trabajadores agrícolas asalariados en el noroeste de México, 1970-1995. Universidad Autónoma de Sinaloa. México.

Pulido Urbano, David, Díaz, Juan Carlos y Hernández, Ricardo (2005). La teoría económica institucional: el enfoque de Nort en el ámbito de la creación de empresas. Investigaciones Europeas de Dirección y Economía de la Empresa, No. 3, Vol. 11, España (pp. 1 15). 
Quevedo Castro, Rosario (1996). La lucha por la tierra en Sinaloa: 1970-1976. Facultad de Historia-Universidad Autónoma de Sinaloa. Tesis de Maestría en Historia Regional, México.

Ramírez Meza, Benito (1987). El movimiento obrero sinaloense. De sus años de formación a la etapa de la crisis, 1875 1934. Tesis de Maestría en Historia Regional. Facultad de Historia-Universidad Autónoma de Sinaloa, México.

Ramírez Meza, Benito (1992). El movimiento obrero sinaloense de sus años de formación al inicio de la etapa cardenista. Revista Clío. No. 5. México (80-85).

Ramírez Meza, Benito (1996). Cárdenas y la clase trabajadora sinaloense. Revista Ciencia y Universidad. No. 9. México (pp.173-180).

Reyna, Leticia (2004). La rebelión campesina de Sierra Gorda (1847-1850. En Friedrich Katz (Editor). Revuelta, rebelión y revolución. La lucha rural en México del siglo XVI al siglo XXI. Ediciones Era. México.

Rivera Calvo, María Elda (2001). Empresarios agrícolas en Ahome (1929-1940). Tesis de Maestría en Historia. Universidad Autónoma de Sinaloa. México.

Román Alarcón, Rigoberto Arturo (2006). La economía del Sur de Sinaloa. DIFOCURUniversidad Autónoma de Sinaloa, México.

Román Alarcón, Rigoberto Arturo (2009). Los Melchers y su actividad empresarial en Mazatlán. Siglos XIX y XX. Guatavo Aguilar Aguilar y Eduardo Frías Sarmiento (coordinadores). Historia de empresarios y grupos de poder en Sinaloa: del porfiriato al salinismo Culiacán. Universidad Autónoma de Sinaloa. México.

Rubio Félix Lázaro (1979). Sinaloa, campo de sangre. SEP. México.

Rubio Ruelas, Baldemar y Jaime F. Hirata Galindo (1985), El movimiento campesino y las invasiones de tierras en Sinaloa durante 1976. En Rubén Burgos (Coordinador), Movimientos sociales en el Noroeste de México. Universidad autónoma de Sinaloa, México.

Sánchez Parra, Sergio Arturo (2011). La Liga Comunista 23 de septiembre en Sinaloa. Los restos de un naufragio: 1974-1976. Anuario de Historia Regional y de las Fronteras. No. 16, Colombia (pp. 243-265).

Sánchez Parra, Sergio Arturo (2012). Estudiantes en armas. Una historia política y cultural del movimiento de los enfermos (1972-1978). Universidad Autónoma de Sinaloa. México.

Sánchez Parra, Sergio Arturo (2013a). Raíces culturales del radicalismo político universitario. El caso de los enfermos de la UAS: 1972-1979. Revista Historia de la Educación Latinoamericana. No. 21, Colombia (pp. 161-190).

Sánchez Parra, Sergio Arturo (2013b). Escritura y revolución. Una historia política de Los Enfermos a través de sus producciones discursivas. Revista de Letras Históricas. No. 4, México (pp. 161-180).

Santos Cenobio, Rafael (2007). "Los enfermos": un movimiento político-armado en Sinaloa, 1072-1976. Tesis de Maestría en Historia de México. Universidad de Guadalajara. México.

Santos Cenobio, Rafael (2013). Entre las aspiraciones agrarias y los vaivenes de la política en Sinaloa, 1915-1969. Tesis de Doctorado en Ciencias Sociales. Universidad de Guadalajara. México.

Schubert, Lorena (1998). Historia de una gesta obrera campesina: 1a SICAE. DIFOCUR. México.

Skocpol, Theda (1984). Los estados y las revoluciones sociales. Un análisis comparativo de Francia, Rusia y China. Fondo de Cultura Económica. México.

Sosa Ortiz, Víctor Hugo (2015). La gestión del agua. Impulsor del crecimiento económico en Sinaloa, 1946-1995. Tesis de doctorado en Economía, Universidad Autónoma de México, México. 
Soto Carballo, Paulina A (2011). Movimiento campesino por la tierra en el norte de Sinaloa, 1968-1976. Tesis de Maestría en Historia. Universidad Autónoma de Sinaloa. México.

Terán Olguín, Lorenzo Q (2006). Corerepe. Ejido y Agrarismo en Sinaloa. Impressart Editorial. México.

Thompson P. Edward (1989). La formación de la clase obrera en Inglaterra. II tomos, editorial Crítica, España.

Tilly, Charles, Louise Tilly y Richard Tilly (1997). E1 siglo Rebelde, 1830-1930. Prensas Universitarias de Zaragoza. España.

Torres Angulo, José (1975). La lucha por la tenencia de la tierra en Sinaloa. Publicación individual, México.

Torrow, Sidney (1997). El poder en movimiento. Los movimientos sociales, la acción colectiva y la política. Alianza Universidad. México.

Tutino, John (1990). De la insurrección a la revolución en México. Las bases sociales de la violencia agraria 1750-1940. Ediciones Era. México.

Tutino, John (2004). Cambio social agrario y rebelión campesina en México Decimonónico: el caso de Chalco. En Friedrich Katz (editor). Revuelta, rebelión y revolución. La lucha rural en México del siglo XVI al siglo XX. Ediciones Era. México.

Valerio Ulloa, Sergio (2008). Redes familiares, empresariales y crediticias en Guadalajara. Siglo XIX. En Celina G. Becerra Jiménez (coordinadora). Elites, redes y vínculos en el Centro Occidente de México. Siglos XVII al XIX. Universidad de Guadalajara. México.

Valerio Ulloa, Sergio (2012). Entre lo dulce y lo salado. Bellavista: genealogía de un latifundio (siglos XVI al XX). Universidad de Guadalajara. México.

Verdugo Rentaría, Miguel (1987). La comercialización del tomate en el valle de Culiacán. Universidad Autónoma de Sinaloa. México.

Villegas Félix, Ramón (2000). La lucha magisterial sinaloense, 1937-1938. Años de su decisión. DIFOCUR. México.

Warman, Arturo (1976). Y venimos a contradecir. Los campesinos de Morelos y el Estado Nacional. Ediciones de Casa Chata. México.

Zavala Zavala, Arturo (2000). Sinaloa. Entre El muchacho alegre y las Hojas de hierba (buena. 1940-1950. En la perspectiva del noroeste. Colegio de Bachilleres del Estado de Sinaloa. México.

Zepeda Patterson, Jorge (1988). Los estudios sobre el campo en México, en Jorge Zepeda Patterson (Editor), Las sociedades rurales hoy. El colegio de Michoacán-CONACYT, México. 